\title{
openheart Pregnancy outcome in women with atrial septal defect: associated with in vitro fertilisation and pre-eclampsia
}

\author{
Sebastian Udholm (D) , ${ }^{1}$ Louise Udholm, ${ }^{2}$ Camilla Nyboe, ${ }^{1}$ \\ Ulrik Schiøler Kesmodel, ${ }^{3}$ Vibeke Elisabeth Hjortdal (1) ${ }^{2}$
}

\begin{abstract}
- Additional material is published online only. To view, please visit the journal online (http://dx.doi.org/10.1136/ openhrt-2019-001148).
\end{abstract}

To cite: Udholm S, Udholm L, Nyboe $\mathrm{C}$, et al. Pregnancy outcome in women with atrial septal defect: associated with in vitro fertilisation and preeclampsia. Open Heart 2019;6:e001148. doi:10.1136/ openhrt-2019-001148

Received 31 July 2019 Revised 13 September 2019 Accepted 14 October 2019

Check for updates

(C) Author(s) (or their employer(s)) 2019. Re-use permitted under CC BY-NC. No commercial re-use. See rights and permissions. Published by BMJ.

${ }^{1}$ Department of Cardiothoracic and Vascular Surgery, Aarhus University Hospital, Aarhus, Denmark

${ }^{2}$ Department of Cardiothoracic Surgery, Rigshospitalet, Kobenhavn, Denmark ${ }^{3}$ Department of Obstetrics and Gynaecology, Aalborg University Hospital, Aalborg, Denmark

Correspondence to

Dr Sebastian Udholm; sebastian. udholm@clin.au.dk

\section{ABSTRACT}

Objective To investigate in vitro fertilisation (IVF) in women with atrial septal defect (ASD), and to examine the maternal characteristics and outcome of pregnancy, as well as the fetal outcome of infants born by women with ASD

Methods We used population-based registries in this nationwide cohort study, including Danish individuals born before 1994 who received an ASD diagnosis between 1959 and 2014. Patients were compared with a random reference sample (ratio of 10 citizens per patient) matched by sex and age. The Danish Medical Birth Register (DMBR) contains data on all pregnancies and births in Denmark from 1977 to present. Risk of IVF treatment as well as maternal, pregnancy and fetal outcomes were compared. Results A total of 2277 Danish patients had a validated ASD diagnosis. Of these, 310 women were identified in the DMBR. Women with ASD had an increased risk of receiving IVF treatment (HR 3.14, 95\% Cl 2.1 to $4.7, \mathrm{p}<0.0001$ ), and a higher proportion of patients received IVF treatment when compared with the reference cohort $(10.6 \%$ vs $3.2 \% ; p<0.001)$. Furthermore, patients had more multiple births. Looking at singleton pregnancies $(n=519)$, preeclampsia occurred more frequently in patients with ASD during pregnancy $(6.7 \%$ vs $2.3 \% ; p<0.001)$. Infants from mothers with ASD were found to have perinatal outcomes comparable to those of infants from the reference group. Conclusion Women with ASD had an increased risk of and received more IVF treatment than the reference group. The outcome of pregnancy in these patients were generally uneventful, however, we did confirm that preeclampsia occurred more frequently.

\section{BACKGROUND}

Improvement in the management of patients with congenital heart disease (CHD) over the last decades has been considerable and, subsequently, the majority of these patients now live well into their childbearing age. ${ }^{12}$

Atrial septal defect (ASD) is one of the most frequent CHDs also in pregnant women. Pregnancy is associated with additional volume loading producing a circulatory burden that, consequently, aggravates the right ventricular volume overload caused by defect. ${ }^{3}$ Many unanswered questions remain

\section{Key questions}

What is already known about this subject?

- Infertility and need for in vitro fertilisation (IVF) have never been examined in patients with atrial septa defect (ASD).

- Indeed, no studies have examined the extent of infertility and IVF in any patients with congenital heart disease.

What does this study add?

- In this nationwide study, we show that women with ASDs have an increased risk of receiving IVF when compared with a reference cohort (HR 3.14, 95\% Cl 2.1 to $4.7, p<0.0001$ )

- Furthermore, we discovered that 3 times as many women with ASD needed IVF when compared with the reference cohort.

We also confirmed that women with ASD experience pre-eclampsia more frequently during pregnancy.

How might this impact on clinical practice?

- Our results present important information for healthcare professionals providing pregnancy counselling for women with ASD trying to conceive.

- Awareness of issues with infertility and increased risk of IVF might increase the chance of a pregnancy.

regarding women with ASD and pregnancy, as issues with infertility and need for in vitro fertilisation (IVF) have never been addressed. Indeed, no studies have, to our knowledge, examined the extent of infertility and IVF in any patients with CHD, and only few studies have investigated the outcome of pregnancy in women with ASDs. ${ }^{4-7}$

Given that most women with ASD reach the fertile age and contemplate pregnancy, healthcare professionals have a difficult task of providing counsel for women trying to conceive. In this study, we investigate if the need for IVF treatment is higher among women with ASD, as well as the associated infertility diagnosis, using the unique Danish registries and comparing outcome with the general population. In addition, we examined 
both the maternal characteristics and outcome of pregnancy in mothers with ASD, as well as the fetal outcome of infants born by women with ASD.

\section{METHODS}

\section{Study population}

We used several medical registries in this nationwide descriptive cohort study. All registered Danish residents are automatically entitled to publicly financed healthcare with equal accessibility for all Danes. Mandatory registration of data from all hospitals and outpatient clinics is collected in numerous nationwide public registries. We used the Danish National Patient Registry (DNPR) to identify all patients diagnosed with an ASD between 1977 and 2017, as this register contains complete and continuously updated data on all Danish residents since its beginning in 1977. To ensure follow-up into adulthood, patients had to be born before 1994. The DNPR has data on all inpatient hospital contacts in Denmark, dates of contact and discharge, surgical procedures and discharge diagnoses coded according to the International Classification of Disease (ICD). ${ }^{8}$ The 8 th edition was used until 1993 and was subsequently replaced by the 10th edition. The ASD diagnosis was validated by two independent physicians through review of hospital records. Patients with concomitant CHD or persisting foramen ovale were excluded. This cohort has been described in a previous study investigating mortality in patients with ASD. ${ }^{9}$ We used the Danish Civil Registration System to draw a random reference sample matched by sex and age with the included patients with ASD, resulting in a ratio of 10 citizens per patient.

The unique personal identification number, assigned to each Danish citizen at birth since 1968, was used to link patients diagnosed with an ASD to another Danish registry: The Danish Medical Birth Register (DMBR). ${ }^{10} 11$ This register contains data on all pregnancies and births in Denmark from 1977 to present. Thus, our study population consisted of women with an ASD diagnosis, registered in the DNPR, present in the DMBR.

\section{IVF and infertility diagnoses}

Fertility treatment is free of charge in Danish public clinics, offering three to six intrauterine insemination treatment cycles and three IVF cycles. We identified IVF treatment in the DNPR by the codes BJFL00 and BJFL00A. Proportions of IVF treatment were reported for both the entire ASD study population (both men and women), and for the identified mothers with ASD in the DMBR. Subgroups of infertility diagnoses were also identified in the DNPR by the codes DN97 to DN979 with additional codes DN80 to DN809 for endometriosis, and DE282 for polycystic ovary syndrome (PCOS). Codes for all variables are provided in online supplementary table 1.

\section{Pregnancy and fetal outcome}

We used the DMBR to obtain information about both maternal, pregnancy and fetal characteristics. All reported measurements and recordings are performed by highly trained healthcare professionals, and registration immediately after birth has been mandatory in Denmark since $1977 .{ }^{11}$ It should be noted that gestational age at birth after 1997 has been based on ultrasound measurements in $>93 \%$ of cases, and that early cord clamping was used nationwide when the DMBR was initiated. Lastly, the untrimmed placenta was weighed in the delivery room by using a digital scale.

\section{Statistics}

Continuous, normally distributed data were reported as mean $\pm \mathrm{SD}$. The unpaired Student's t-test was used for normally distributed data. Categorical variables were summarised by percentages or frequencies. Comparisons of categorical maternal, pregnancy and fetal characteristics between patients and the general population were performed by Fisher's exact test. Cox proportional regression analysis was used to compute HRs for IVF treatment in patients with ASD comparing them with the reference cohort. Analyses were adjusted for smoking, parental age and parity. Statistical significances were defined as a $p$ value $<0.05$. Missing data were found in body mass index (BMI), height and smoking, as these variables were not systematically implemented in the registries from the beginning of registration. Missing was dropped from the analyses, and values are presented in the relevant tables. All analyses were performed using Stata IC V.15.1 (StataCorp, College Station, Texas, USA).

\section{RESULTS}

\section{Study population}

A total of 4445 patients born before 1994 and diagnosed with an ASD before 2013 were identified in the DNPR. We excluded 609 patients due to concomitant CHD. Further 651 patients were excluded as their hospital record was missing, thereby leaving 3185 patients for validation. Lastly, we excluded patients with a persisting foramen ovale or no ASD, providing a final total of 2220 patients with a confirmed ASD diagnosis. Additionally, a matched comparison cohort of 22565 were included. Of the 2220 identified patients, 310 female patients (mean age 29.9 years) were present in the DMBR. We identified 3677 females in the reference group. Maternal characteristics for both groups are summarised in table 1.

No differences in age, smoking, prepregnancy BMI or number of previous miscarriages were found when comparing patients with the reference group.

\section{IVF treatment and births}

The prevalence of IVF treatment in the entire ASD cohort $(n=2220)$ was significantly higher when compared with the general population $(1.9 \%$ vs $0.8 \%$; $<<0.001)$. Looking at the DMBR, mothers with ASD $(n=310)$ had a total of 559 births, of which 40 births $(7.2 \%)$ were multiples (table 1). In comparison, the 3677 female references gave birth 6580 times with significantly fewer $(3.7 \%$; $\mathrm{p}=0.001$ ) being of multiples. A significant increase in IVF 
Table 1 Maternal characteristics (patients with ASD compared with the general population)

\begin{tabular}{|c|c|c|c|}
\hline Variable & $\begin{array}{l}\text { Mothers } \\
\text { with ASD } \\
\mathrm{n}=310\end{array}$ & $\begin{array}{l}\text { References } \\
n=3677\end{array}$ & $P$ value \\
\hline $\begin{array}{l}\text { Maternal age, years } \\
(\text { mean } \pm S D)\end{array}$ & $29.9 \pm 5.0$ & $29.9 \pm 4.9$ & 0.902 \\
\hline $\begin{array}{l}\text { Maternal prepregnancy BMI, } \\
\mathrm{kg} / \mathrm{m}^{2 \star} \\
(\mathrm{mean} \pm \mathrm{SD})\end{array}$ & $24.1 \pm 4.7$ & $24.6 \pm 8.2$ & 0.242 \\
\hline $\begin{array}{l}\text { Height, } \mathrm{cm}^{\star} \\
\text { (mean } \pm \text { SD) }\end{array}$ & $168.9 \pm 50.8$ & $166.3 \pm 24.1$ & 0.092 \\
\hline Smoker, n (\%)† & $60(21.5)$ & $661(19.7)$ & 0.705 \\
\hline $\begin{array}{l}\text { Paternal age, years } \\
(\text { mean } \pm S D)\end{array}$ & $33.0 \pm 6.1$ & $32.3 \pm 5.6$ & 0.007 \\
\hline Births, $n$ & 559 & 6580 & - \\
\hline Singleton birth, $n$ & 519 & 6324 & - \\
\hline Multiple birth, $n$ & 40 & 256 & - \\
\hline Multiple birth, \% & $7.2 \%$ & $3.9 \%$ & 0.001 \\
\hline IVF treatment, n (\%) & $33(10.6)$ & 119 (3.2) & $<0.001$ \\
\hline $\begin{array}{l}\text { Maternal age at IVF } \\
\text { treatment, years } \\
\text { (mean } \pm S D \text { ) (range) }\end{array}$ & $\begin{array}{l}29.6 \pm 0.90 \\
(21.3-40.1)\end{array}$ & $\begin{array}{l}30.8 \pm 0.36 \\
(20.8-41.4)\end{array}$ & - \\
\hline $\begin{array}{l}\text { Multiple pregnancy following } \\
\text { IVF, } \mathrm{n}(\%)\end{array}$ & $8(20.0)$ & $24(9.4)$ & 0.055 \\
\hline Previous miscarriage, $\mathrm{n}(\%)$ & $54(17.4)$ & $602(16.4)$ & 0.753 \\
\hline
\end{tabular}

*Data were missing for BMI and height in 139 mothers with ASD and 1487 references.

†Data were missing for smoking in 32 mothers with ASD and 336 references.

ASD, atrial septal defect ; BMI, body mass index; IVF, in vitro fertilisation.

treatment was evident when comparing female patients with ASD (10.6\%) with women from the general population $(3.2 \% ; \mathrm{p}<0.001)$. The risk of receiving IVF treatment was increased in patients with ASD compared with the reference group (adjusted HR 3.14, 95\% CI 2.1 to 4.7, $\mathrm{p}<0.0001)$. The distribution of infertility diagnoses among patients and references who received IVF treatment did not differ between the two groups (table 2).

\section{Outcome of pregnancy}

We found 519 singletons pregnancies in the group of women with an ASD, and 6324 singleton pregnancies in the reference group. All singleton pregnancy outcome data are presented in table 3 .

A significantly higher proportion of patients with ASD experienced pre-eclampsia during their pregnancy when compared with the general population. Correspondingly, patients with ASD also had more visits to specialists. Other pregnancy complications including preterm prelabour rupture of membranes, polyhydramnios, placenta accreta and placental abruption did not differ between patients with ASD and the general population.
Table 2 Infertility diagnoses among mothers with ASD and general population receiving IVF treatment

\begin{tabular}{llcl}
\hline & $\begin{array}{l}\text { ASD } \\
\text { mothers } \\
\text { receiving } \\
\text { IVF } \mathbf{n = 3 3}\end{array}$ & $\begin{array}{l}\text { References } \\
\text { receiving IVF } \\
\mathbf{n = 1 1 9}\end{array}$ & P value \\
\hline Endometriosis, $\mathrm{n}(\%)$ & $2(6.1)$ & $8(6.7)$ & 0.100 \\
\hline $\begin{array}{l}\text { Polycystic ovary } \\
\text { syndrome, } \mathrm{n}(\%)\end{array}$ & $0(0)$ & $5(4.2)$ & 0.586 \\
\hline Anovulation, $\mathrm{n}(\%)$ & $2(6.5)$ & $7(5.9)$ & 1.000 \\
\hline Tubal factor, $\mathrm{n}(\%)$ & $2(6.1)$ & $18(15.9)$ & 0.247 \\
\hline Uterine factor, $\mathrm{n}(\%)$ & $1(3)$ & $2(1.7)$ & 0.523 \\
\hline Male factor, $\mathrm{n}(\%)$ & $4(12.1)$ & $18(15.3)$ & 0.786 \\
\hline Other causes, $\mathrm{n}(\%)$ & $29(87.9)$ & $99(83.2)$ & 0.601 \\
\hline
\end{tabular}

Patients might have more than one diagnosis.

ASD, atrial septal defect ; IVF, in vitro fertilisation.

\section{Fetal characteristics}

Generally, infants born by mothers with ASD displayed similar fetal characteristics as infants in the general population (table 4).

Birth weight was found to be slightly, however significantly, lower in infants from mothers with ASD when compared with the general population $(3466.4 \pm 585.7 \mathrm{~g}$ vs $3524.3 \pm 586.4 \mathrm{~g} ; \mathrm{p}=0.032$ ). Variables such as lengths, head circumference and waist circumference did not differ between the two groups.

\section{DISCUSSION}

This is the first study to investigate IVF and infertility diagnoses in any $\mathrm{CHD}$, and the first nationwide study to examine pregnancy and fetal outcome in mothers with ASD. Our cohort study showed that women with an ASD diagnosis had an increased risk and a higher prevalence of IVF treatment, and also had more multiple births. Additionally, it confirmed that pre-eclampsia occurred more frequently in patients with ASD during pregnancy. Infants from mothers with ASD were found to have perinatal outcomes comparable to those of infants from the general population despite a slightly lower birth weight.

A substantial proportion of women with ASDs needed help to conceive, a number well above the need found in the reference cohort. Whereas the increased number of multiple births among women with ASD is likely explained by the increased levels of IVF, our data do not provide an explanation for the IVF usage itself. In this regard, it can only be speculated if patients with a an ASD diagnosis who experience difficulties conceiving would be referred to IVF treatment at an earlier stage than patients without a diagnosis, or if this outcome may reasonably be attributed to the late consequences of the haemodynamic effects of the ASD. Despite being a common clinical problem, and an issue that might be concerning to many women, most questions regarding infertility and fertility treatment in patients with CHD remain unanswered. Indeed, these 
Table 3 Pregnancy-related outcome in all single pregnancies among female patients with ASD compared with the general population

\begin{tabular}{lccc}
\hline Variable & $\begin{array}{l}\text { Single pregnancies patients } \\
\text { with ASD } \mathbf{n = 5 1 9}\end{array}$ & $\begin{array}{l}\text { Single pregnancies } \\
\text { references } \mathbf{n = 6 3 2 4}\end{array}$ & P value \\
\hline $\begin{array}{l}\text { Gestational age, days } \\
\text { (mean } \pm \text { SD) }\end{array}$ & $277.5 \pm 13.4$ & $278.7 \pm 13.1$ & 0.048 \\
\hline Midwife visits, $\mathrm{n}$ & 5.0 & 4.9 & 0.444 \\
\hline Physicians visits, $\mathrm{n}$ & 3 & 3 & 0.135 \\
\hline Specialists visits, $\mathrm{n}$ (min-max) & $2(0-9)$ & $1(0-9)$ & $<0.001$ \\
\hline PPROM, $\mathrm{n}(\%)$ & $24(4.6)$ & $270(4.3)$ & 0.653 \\
\hline Placenta previa, $\mathrm{n}(\%)$ & $3(0.6)$ & $25(0.04)$ & 0.001 \\
\hline Placental weight, $\mathrm{g}$ & $635.3 \pm 215.7$ & $651.5 \pm 180.3$ & 0.055 \\
(mean \pm SD) & $4(0.8)$ & $39(0.6)$ & 0.565 \\
\hline Polyhydramnios, $\mathrm{n}(\%)$ & $35(6.7)$ & $142(2.3)$ & $<0.001$ \\
\hline Pre-eclampsia, $\mathrm{n}(\%)$ & $114(22.0)$ & $1160(18.3)$ & 0.046 \\
\hline Sectio, $\mathrm{n}(\%)$ & $13(2.5)$ & $107(1.7)$ & 0.165 \\
\hline Sectio mothers wish, $\mathrm{n}(\%)$ & $5(1)$ & $41(0.7)$ & 0.394 \\
\hline Placenta accreta, $\mathrm{n}(\%)$ & $2(0.4)$ & $17(0.3)$ & 0.651 \\
\hline Hemoperitoneum, $\mathrm{n}(\%)$ & $4(0.8)$ & $66(1)$ & 0.819 \\
\hline Intrauterine asphyxia, $\mathrm{n}(\%)$ & $6(1.1)$ & $36(0.6)$ & 0.131 \\
\hline Placental abruption, $\mathrm{n}(\%)$ & & & \\
\hline
\end{tabular}

Gestational age was slightly lower in the patients with ASD $(277.5 \pm 13.4$ vs $278.7 \pm 13.1 ; p=0.048)$.

ASD, atrial septal defect ; PPROM, preterm prelabour rupture of membranes.

aspects and outcome hereof are only described in a few subtypes of congenital lesions and in small study samples. In women with the Fontan circulation, the outcome of pregnancy showed increased risk of miscarriage, preterm birth and poor fetal growth. ${ }^{12}$ In contrast, other studies on women with Tetralogy of Fallot and Ebstein's anomaly showed that the fertility in these patients was not affected,

Table 4 Fetal outcome in all single pregnancies among female patients with ASD compared with the general population

\begin{tabular}{|c|c|c|c|}
\hline Variable & $\begin{array}{l}\text { Singletons } \\
\text { from } \\
\text { mothers } \\
\text { with ASD } \\
\mathrm{n}=519\end{array}$ & $\begin{array}{l}\text { Singletons } \\
\text { from } \\
\text { reference } \\
\text { mothers } \\
b=6324\end{array}$ & $P$ value \\
\hline $\begin{array}{l}\text { Length at birth, } g \\
\text { (mean } \pm S D)\end{array}$ & $51.5 \pm 6.0$ & $51.6 \pm 4.9$ & 0.494 \\
\hline $\begin{array}{l}\text { Birth weight, g } \\
\text { (mean } \pm \text { SD) }\end{array}$ & $3466.4 \pm 585.7$ & $3524.3 \pm 586.4$ & 0.032 \\
\hline $\begin{array}{l}\text { Head circumference, } \\
\mathrm{cm} \\
(\text { mean } \pm S D)\end{array}$ & $34.3 \pm 6.4$ & $34.4 \pm 5.0$ & 0.472 \\
\hline $\begin{array}{l}\text { Waist circumference, } \\
\mathrm{cm} \\
(\text { mean } \pm S D)\end{array}$ & $32 \pm 7.0$ & $32 \pm 6.7$ & 0.935 \\
\hline Stillborn, $n$ & 2 & 18 & 0.661 \\
\hline Sepsis, n (\%) & $5(1)$ & $92(1.5)$ & 0.444 \\
\hline
\end{tabular}

ASD, atrial septal defect . perhaps suggesting that infertility issues may be related to specific lesions and, therefore, affects the CHD population differently. However, the small sample sizes found in both studies might undermine their reliability as both hold a significant risk of being underpowered. Whether our findings are related to differentiated algorithms for referral to IVF treatment, alternated haemodynamics or simple genetics is not known, and, consequently, the pathophysiological basis of this unexpected finding deserves further investigation.

The increased prevalence of pre-eclampsia in women with ASD has been described previously in smaller cohorts from Dutch and Belgian registries, reporting almost identical results as ours. Interestingly, similar findings have been found in healthy women with children with ASD. ${ }^{13}{ }^{14}$ Indeed, ASDs in children were strongly associated with maternal early preterm pre-eclampsia (OR $12.0,95 \%$ CI 8.96 to 16.1$)$ and late perm pre-eclampsia. ${ }^{13}$ These associations indicate that the same pathophysiological mechanisms might be involved in the pathogenesis in both pre-eclampsia and ASD. Several studies have already suggested angiogenetic imbalance as a key component contributing to the pathogenesis in both congenital heart defects in general and preterm pre-eclampsia. ${ }^{15-17}$ While speculative, abnormal heart development could be caused by an angiogenetic imbalance in the fetus with ensuring anti-angiogenesis at the trophoblast stage, and a maternal anti-angiogenic state might cause the following cascade of events: reduced trophoblast invasion of the spiral arteries, hypoxia in the placenta, hypoxia in the 
fetus, overproduction of anti-angiogenic factors in the fetus and abnormal heart formation. No matter what the cause, the strong associations demonstrated between preeclampsia and ASD lends further support to the notion that there are unforeseen challenges to having an ASD that cannot be explained by the contemporary haemodynamic effects.

Finally, it has been suggested that reduced placental perfusion may cause pre-eclampsia, however, we do not expect diminished cardiac output and, subsequently, reduced blood flow through the placenta in women with ASD. ${ }^{18}$

Given the adverse events, including higher rates of IVF treatment and a higher prevalence of pre-eclampsia during pregnancy, it was reassuring that fetal outcome in offspring of women with ASDs were comparable to the reference cohort. Nonetheless, our findings did suggest that the birth weight in these infants is lower than normal. This is in accordance with the findings by Yap et al, demonstrating significantly lower birth weight and higher risk of being small for gestational age in offspring of mothers with ASDs. ${ }^{7}$ Interestingly, these results were associated with the corrective status of the defect, as only offspring of women with an unrepaired ASD experienced these adverse outcomes. This association adds to the conclusion of a novel study characterising the natural history of unrepaired ASD, describing how a defect 'that is considered insignificant and not warranting closure in early life cannot be considered to be a benign lesion' ${ }^{19}$ The demonstrated fetal outcome also reflects that of infants born with ASD from healthy parents, as lower birth weight, normal head circumference and normal placental weight have been demonstrated in these infants. ${ }^{20} 21$

\section{Limitations}

Our data did not suggest an explanation for the higher usage of IVF treatment among women with ASD. Whether higher awareness among obstetricians when confronted with a mother with a CHD, including ASD, results in earlier referral for IVF treatment is unknown. Additionally, it is unknown if any ASDs were diagnosed during the workup prior to IVF treatment, causing an over-representation.

We did not address the potential effects of social skewness. People from lower social groups conceive earlier, and recent unpublished studies show a higher proportion of patients with ASD in these social groups. It might be that patients with ASD try to conceive at a younger age, thereby, identifying fertility issues earlier than an age-matched reference group and, consequently, receive IVF treatment at a younger age.

Finally, interpreting register-based data inherently has some limitations as the validity of the diagnoses in the registries depend of the physicians generating the data. However, all ASD diagnoses given in the DNPR had been manually validated leaving very little error for potential misreporting and under-reporting or over-reporting. ${ }^{22} 23$
Diagnoses for IVF treatment and infertility have not been formally validated, but some diagnoses such as PCOS appear to be substantially under-reported in the DNPR.

\section{CONCLUSION}

In this nationwide study, women with ASD had an increased risk and a higher prevalence of IVF treatment, and more multiple births. The outcome of pregnancy in these patients were generally uneventful, however, we did confirm that pre-eclampsia occurred more frequently, perhaps suggesting similar pathophysiological mechanisms. Despite the increased risk for needing IVF treatment and greater risk of pre-eclampsia, the fetal outcome was, reassuringly, comparable to the healthy background population. Our results highlight a new area of interest for future research, as fertility treatment and infertility need to be investigated throughout the spectrum of CHD.

Acknowledgements The authors would like to thank research secretary Jette Breiner for her highly valuable contributions.

Contributors SU, CN, VH: construction of idea, planning of research, conduct of research, manuscript writing and revision. LU: intellectual and research review, manuscript writing and revision. USK: idea inception and formulation, data interpretation, manuscript writing and revision.

Funding This study was funded by Aarhus University and Karen Elise Jensens Foundation.

Competing interests None declared.

Patient consent for publication Not required.

Ethics approval This study was approved by The Central Denmark Region Research Committee and the National Board of Health (j.nr. 7-604-04-2/193/KWH).

Provenance and peer review Not commissioned; internally peer reviewed.

Data availability statement All data relevant to the study are included in the article or uploaded as supplementary information.

Open access This is an open access article distributed in accordance with the Creative Commons Attribution Non Commercial (CC BY-NC 4.0) license, which permits others to distribute, remix, adapt, build upon this work non-commercially, and license their derivative works on different terms, provided the original work is properly cited, appropriate credit is given, any changes made indicated, and the use is non-commercial. See: http://creativecommons.org/licenses/by-nc/4.0/.

\section{ORCID iDs}

Sebastian Udholm http://orcid.org/0000-0002-3929-5120

Vibeke Elisabeth Hjortdal http://orcid.org/0000-0002-8047-0015

\section{REFERENCES}

1 Warnes CA, Liberthson R, Danielson GK, et al. Task force 1: the changing profile of congenital heart disease in adult life. J Am Coll Cardiol 2001;37:1170-5.

2 Larsen SH, Olsen M, Emmertsen K, et al. Interventional Treatment of Patients With Congenital Heart Disease: Nationwide Danish Experience Over 39 Years. J Am Coll Cardiol 2017;69:2725-32.

3 Thornburg KL, Jacobson S-L, Giraud GD, et al. Hemodynamic changes in pregnancy. Semin Perinatol 2000;24:11-14.

4 Zuber M, Gautschi N, Oechslin E, et al. Outcome of pregnancy in women with congenital shunt lesions. Heart 1999;81:271-5.

5 Khairy P, Ouyang DW, Fernandes SM, et al. Pregnancy outcomes in women with congenital heart disease. Circulation 2006;113:517-24.

6 Drenthen W, Pieper PG, Roos-Hesselink JW, et al. Outcome of pregnancy in women with congenital heart disease. A literature review. J Am Coll Cardiol 2007;49:2303-11.

7 Yap S-C, Drenthen W, Meijboom FJ, et al. Comparison of pregnancy outcomes in women with repaired versus unrepaired atrial septal defect. BJOG An Int J Obstet Gynaecol 2009;116:1593-601.

8 Lynge E, Sandegaard JL, Rebolj M. The Danish national patient register. Scand J Public Health 2011;39:30-3. 
9 Nyboe C, Karunanithi Z, Nielsen-Kudsk JE, et al. Long-Term mortality in patients with atrial septal defect: a nationwide cohortstudy. Eur Heart J 2018;39:993-8.

10 Schmidt M, Pedersen L, Sørensen HT. The Danish civil registration system as a tool in epidemiology. Eur J Epidemiol 2014;29:541-9.

11 Bliddal M, Broe A, Pottegård A, et al. The Danish medical birth register. Eur J Epidemiol 2018;33:27-36.

12 Cauldwell M, Von Klemperer K, Uebing A, et al. A cohort study of women with a Fontan circulation undergoing preconception counselling. Heart 2016;102:534-40.

13 Boyd HA, Basit S, Behrens I, et al. Association between fetal congenital heart defects and maternal risk of hypertensive disorders of pregnancy in the same pregnancy and across pregnancies. Circulation 2017;136:39-48.

14 van Gelder M, Van Bennekom CM, Louik C, et al. Maternal hypertensive disorders, antihypertensive medication use, and the risk of birth defects: a case-control study. BJOG: Int J Obstet Gy 2015;122:1002-9.

15 Levine RJ, Maynard SE, Qian C, et al. Circulating angiogenic factors and the risk of preeclampsia. N Engl J Med 2004:350672-83.
16 Sliwa K, Mebazaa A. Possible joint pathways of early pre-eclampsia and congenital heart defects via angiogenic imbalance and potential evidence for cardio-placental syndrome. Eur Heart J 2014;35:680-2.

17 Llurba E, Sánchez O, Ferrer Q, et al. Maternal and foetal angiogenic imbalance in congenital heart defects. Eur Heart J 2014;35:701-7.

18 Roberts JM, Gammill HS. Preeclampsia: recent insights. Hypertension 2005;46:1243-9.

19 Udholm S, Nyboe C, Karunanithi Z, et al. Lifelong burden of small unrepaired atrial septal defect: results from the Danish national patient registry. Int J Cardiol 2019;283:101-6.

20 Matthiesen NB, Henriksen TB, Gaynor JW, et al. Congenital heart defects and indices of fetal cerebral growth in a nationwide cohort of 924422 Liveborn infants. Circulation 2016;133:566-75.

21 Matthiesen NB, Henriksen TB, Agergaard P, et al. Congenital Heart Defects and Indices of Placental and Fetal Growth in a Nationwide Study of 924422 Liveborn Infants. Circulation 2016;134:1546-56.

22 Nyboe C, Olsen MS, Nielsen-Kudsk JE, et al. Atrial fibrillation and stroke in adult patients with atrial septal defect and the long-term effect of closure. Heart 2015;101:706-11.

23 Nyboe C, Olsen MS, Nielsen-Kudsk JE, et al. Risk of pneumonia in adults with closed versus unclosed atrial septal defect (from a nationwide cohort study). Am J Cardiol 2014;114:105-10. 